\title{
Visual Code Across Borders. Visual Communication as the Answer to Intercultural Management Dilemmas
}

\begin{abstract}
The paper focuses on the visual communication channel and it's practical implications to the intercultural management practice. Introducing theoretical framework provides arguments for the increasing role of the pictures in the image economy, where esthetics and visual branding are the core elements. Two main fields of business applications of visual channels are drawn in the article: external consumers communication and internal organizational communication. Author's definition of visual marketing communication (VMC) is provided and the semiotic approach is recommended for the culturally rooted customer communication that increases consumption globally, while information design and infographics are the visual messages suggested for the second field, which is internal, employees communication management.

Keywords: image economy, intercultural management, visual communication, integrated marketing communication, information design, infographics
\end{abstract}

Contemporary social life is saturated with data and information. The digital technology, mass media culture and globalization are most commonly identified factors responsible for this fact. The sources of this overload phenomenon are various, but interesting from the point of view of business practice is one of its consequences. The iconic turn is emerging, images are crucial and immanent part of human communication process. The scientists from various fields has been studying visual phenomenon and their role in contemporary culture [Machin D., 2014]. Anthropologists mainly focus on meaning of human gesture and expression among people evoked by and through pictures, archeologists study meaning of alicja.waszkiewicz@id.uw.edu.pl 
visual cultural artifacts through nowadays knowledge grid. Philosophers of mind are occupied by the nature of visual signifiers in the brain and art historians trace patterns, techniques and materials of paintings.

Also applied sciences deal with the theme. In the management studies what can be the most useful, these are the discoveries of psychologists who examine the way the brain and psyche of the customers process visual information for example during shopping. Furthermore the design studies provide valuable descriptions of the best way to transmit accessible, appropriate and attractive product or service information that can be extremely helpful for IT design and proper construction of effective online business channels. Last but not least, are media studies that research visual media industry, the nature of representation and persuasion, as well as neoliberal economy ideology transmission through images. And contemporary business cannot function properly without relations with media. Extensive and multifaceted field of visual studies is not much as defined discipline, but a broad set of overlapping concerns. Nevertheless, visual embrace to social life can be unquestionably seen in economy. The power of the visual communication definitely determines the business practice and it has growing influence on international management and this article will point out two main fields were this occurrence can be observed. The paper also presents list of examples what types of creative visual massages can be useful to enhance the management performance on both defined areas.

\section{International business communication in times of image economy}

According to Entwistle [2002, pp. 317-339] we live in times of aesthetic economy, where financial calculations are intertwined with cultural trends, bound to forms of cultural knowledge and to social, cultural and institutional relations. In contemporary world capital matters but more and more as well counts beauty, splendor, acquired taste and visual recordings. Fluidity of the media technologies permitting the emergence of new forms of visual expression (like infographics on Pinterest or selfies on Instagram) relates growingly with business practice. New professions, like bloggers and vloggers, conquered the mediasphere and now they need to be taken under serious consideration by majority of marketers and managers. Virtual and visual media creators' opinions matter, they are trendsetters and their photography and comments often condition consumers choices. Most vivid this influence is in fashion industry, it's also quite intense in beauty sector and luxury brands categories.

In addition Shroeder [2004] coins term emphasizing role of the visual in business and calls it 'image economy'. In visual communication picture serves as a stimulus in constructed message, a text or a representation that drives cognition, interpretation and influence preference of the recipient, as a result it often stimulates consumption. 
Of course cultural meaning is not facilitated only by pictures, public sphere meaning attributed to products and services vacillate between reconfigurations of written, textual and visual systems. However, it's the visual that is much more persuasive in the cursory, brief reception and non-analytical interpretation of advertising messages. Consumer attention span on the marketing message takes only few seconds. Navigating dense media landscape is daunting and very rarely relates on long textual messages. Nowadays globalised world of international supply and demand it's very crowded and highly competitive. It's not the product or service but brands that matter. Perceived in a fast way during volatile market cycles, it's the symbolic meaning of brand logo, its colors and imaginary world that anchors the attention of the over stimulated consumer. Contemporary image economy trades with visual representations of the better life and it happens on the global scale. Not only for the customers but also for international corporations members welldesigned information is stimulating, attractive and engaging. These qualities pique interest in both groups even before information is processed or internalized. In that case aesthetics are not superficial, it's essential to get people's attention.

It appears that the visual communication is the important component in the plurality of contemporary business. The approach to the construction and reading of images in company's practice addresses two different publics in two main management areas, these are: consumer brand communication and employees organizational communication. Both will be described in the following parts of the article.

\section{Intercultural consumer brand communication through visual ICM channels}

To reach the clients grouped in various publics organization is leading strategic, ongoing, multichannel, measurable and diversified communication practice. Nowadays it's been proceeded largely through visual channels. As Kliatchko [2005, p. 23] proved in his literature review on integrated marketing communication definitions, "IMC is the concept and process of strategically managing audiencefocused, channel-centered, and results-driven brand communication programmes over time". ICM conception inserts various communication disciplines into holistic viewpoint, it draws from methodologies, experiences and tools of both public relations and marketing. Integration drivers are both market-based, to avoid audience fragmentation, as well as organizational-based, to increase accountability, positioning and improve efficiency, increasing profits in the end [Cornelissen J., 2009]. Contemporary ICM main goal is establishing long-lasting relationship, consumers' loyalty and consumption stimulation, and the axis used for that purpose is the brand. What's more, brand is being constructed through visual language. Looking from the visual communication perspective, there are particular visual 
marketing tools listed below:

- corporate identity system, especially: logo, colors and typography

- packaging

- pack shots

- infographics

- ATL messages

- ambassador

- leaflets, posters and catalogs

- layout of the website (in particular online store)

- advertising films and audiovisual materials (e. g. virtual tour)

- visual messagesdedicated for the online platforms and social media, like Instagram, Facebook, You Tube, Pinterest

- special events

- building / headquarters of the organization

- visual merchandising

Visual marketing communication is to establish a contact and in the long run a bond with the customer through brand images used in ICM. By visual marketing communication (VMC) we may mean acts of representation where a marketer is an economic text maker, a sender who uses a spectrum of visual resources to communicate a set of organization ideas, attitudes and values to different publics. The recognition of designed images exist within a social structure, images are seen by the receivers and deciphered from a particular cultural perspective. VMC should be audience-specific. Some forms of visual messages may claim to the modernist objectives of universality and globalization, but most of the contemporary brand communication operates within more limited, national and culturally-rooted boundaries. Culture influence shared conceptual maps and encrypts the codes which govern the visual relationships of translation between them.

Concerning visual brand communication tools, some of them may use colors, shapes and typeface to provoke particular emotional response among customers, refer to universal values (like red to connote love). For, example sans serif typeface is often used to invoke modernity, while Spencerian script (known from CocaCola logo) looks like hand written and may connote tradition and individuality. But trans-national corporations communication strategy needs to be audiencefocused to be successful. More and more TNCs relies on semiotic studies to "translate" their brand values from one cultural context to another [Oswald L., 2015]. Semiotic approach becomes commonly used paradigm for visual studies [Rose G., 2012] also in business practice. Semiotics adapts linguistic theory to the study of media saturated with visual signs and anchors them in the culture of the consumers. As Oswald [2012, p 4] emphasizes "semiotics transcendent the analysis of communication per se and can be used strategically to align the brand with 
its heritage and positioning and clarify competitive distinctions". That goes along with the theoretical definition and business practice of ICM, mentioned above in the text. The underlying assumption states that there is the mutual influence of the sender and recipient of the marketing messages and socially constructed, local lenses associated with ethnic subculture are unique. This should be taken under consideration for advertising and PR campaigns using visual tools, designed for different multicultural markets during management practice for a global brand.

The issue is not new, however the tools to deal with the dilemma are novel. Rozkwitalska [2009, pp. 93- 95] states that the problem of cultural differences can be found in theories borrowed from cross-cultural management field as well as developed independently by international business theorists. The author emphasizes that on the level of TNCs it's 'the opportunist' strategy that works the best, means cultural cooperation, not authoritarian implementation of the senders strategies without negotiating them with recipients in their cultural context. 'Managing international activities means managing separate functions, like human resources, marketing, finance, production, research and development, etc. The first two are culturally sensitive in particular' [Rozkwitalska M., 2009, p 96]. Marketing visual signs may change meaning as they move from one culture to the next in global marketing, from one point to the next in global visual socially-created media sphere. For example, the Malboro cigarette brand had to adapt its visual signs in advertising billboards when entering to China market, as classic American cowboy icon with non-Asian face wouldn't represent the target. So the actor was changed to resemble Chinese, however, other signs stayed the same: cowboy hat, cigarette in the mouth, casual shirt, wild landscape in the background and of course unchanged was logo and singular typeface of Malboro.

Another global brand from FMCG market, Burger King had a creative concept for international campaign that incorporates iconic signs in the form of real heroes from different cultures that for the first time taste the Whooper sandwich. "Take people that have never before experienced a burger, prove that they've never before experienced a burger with the fact that their language doesn't even contain a word for burger, and then give them your burger and your competitor's burger to see which one they like more. Film the whole process (including the always important making of footage), stitch together a convincing story line, and call it a day", wrote adman Cory O'Brien on his blog "The Future of Ads". The successful campaign not only has persuasive meaning concerning the transparency and credibility of the intercultural burger testers, but also shows Burger King as a global brand and what's more the commercial can be used all around the globe. The last argument is important from the intercultural management cost cutting. Just translate the slogans in the ad, pictures in the whole movie stay the same.

The two examples shows two strategies, however both taking under consideration 
the need of incorporation of cultural signs knowledge. Some brands like Marlboro maintain in the visual marketing channels the frame of the original market message(eg. cowboy figure) and only adjust particular signs (eg. face of the cowboy) to the new cultural context. On the other hand, as shows Whopper campaign, one might already on the level of TNC headquarter marketing department, creating the message that includes a choice of signs from different cultures. In both cases, comprehensive cultural analysis using visual semiotics methodology seems recommended.

\section{Visual employees internal communication}

Visual communication in the international business practice has also second field of application. Except external, brand communication to the customers and stakeholders, it's the internal, employees communication that underlines everyday management practice. Within particular organizational culture of international company there are many channels of information transmission, one may say that even too many. Interchange of thoughts, connection, is fundamental for company's executive processes and it's not an easy task, especially if conducted globally. To create messages that are received, properly deciphered, internalized and understood, messages that are able to switch the workers mindset from off to on, from passive to active, to be persuasive and more over to achieve all of it in the multicultural environment, becomes very challenging task. Using visualization to synthesize ideas appears to be not only an effective medium, it's the type of communication employees brains crave. Both human resources (HR) well as public relations (PR) departments may join forces in this activities, following gaining support among top managers. The development of visual channels becomes necessity. It's happening already, through the virtual tools of communication, through world wide web and company's intranet, but not only. How Ingledew [2011, p 9], put it straightforward: 'Clearly communicating is not simply a matter of creating visually striking images that capture the eye of the viewer, it's about capturing their brain. You must create ideas that ambush the mind and thoughts, and execute these ideas in fresh and exciting visual ways."

In the literature there are two main terms used for the visual display of the information and both can be successfully used in internal communication in the international environment. These are information design items and infographics [Meirelles I., 2013 p 10] and both are utilized as for mapping abstract data to the form of visual representation that makes facts and figures easier to be understood. Information design (also called as "infovis") involves the design of systems. It can be exemplified by the information arrangement (like headquarter and company's regions map, delivery logistics tracks), wayfinding systems (office numbers and names, exits, conference rooms, exhibits centers routs ect.) or visualization of 
the statistics. Infographics stands for visual displays in which graphics (e.g. map, illustration, diagram) communicate information together with verbal forms. They can range from simple diagram of organizational structure were squares and boxes denote company's departments with their horizontal or vertical interdependencies to metaphorical representations, like using symbols of a tree or an iceberg to connote process of company's origin or hidden agenda (iceberg part under water). Infogaphics in the service of company's internal communication may be useful messages in organizational media (corporate press) as well as visual tools during trainings, briefings, international video calls, HR meetings. To draw a mission, make hash tag cloud for an event, visualize change process, create pictorial representations of sales plan ect., these are some of the examples. Visualization of information has a unique function because it shows the structure of the object, the scale and scope or other phenomenon visible at first glance, despite the cultural background and language of the employee. It's universal as the biology of visual perception process. Infovis have to be processed cognitively, with more attention and focus and longer than simple photo. Infographics are powerful tools in explaining the causes and dynamics of the processes especially in complex multicultural environment, they are also commonly used in global media.

Such forms of internal visual communication may be static (e.g. not moving organization map on PPT slide), dynamic (e.g. short illustrative video of company's recruitment process in the illustrative form) or interactive (for example application with some charts that change contents depending on employees cursor movement). Concerning content of visual forms that represents company's information, it can be categorized as: non-numeric (infographics with flags representing TNC global positions), descriptive (dress code illustration), multidimensional (merging or change process in the firm).

Being ubiquitous in modern urban landscapes, infovis and infographics are rebranded knowledge assemblages for an information era. Designers may use webbased tools to create momentary infographics (for company's anniversary, local national holidays ect.) that are rapidly disseminated via social media networks or other internal media. Graphic data displays utilize established design principles (like the rules of Gestalt psychology) to increase the impact of internal, organizational research, to reach not only the eyes but the mind of the employees all over the world, despite the cultural differences in symbolic representation connotations. These messages are universal. However, inexpensive tools can provide graphic elements and design templates, the effective information visualizations definitely require compelling data and logical narratives to involve organization members. Don't tell, show it to the people, but not forget to explain them the context; it's the essential visual tip for international managers. The Figure 1 from portal infosthetics. com shows the interdependencies between function, form, integrity and 
interestingness. This field demands more research, nevertheless acknowledging its importance and understanding the biologically rooted basics of human image perception is the opening step for international communication management.

Figure 1 Interdependencies between design, form and practical application of information visualization.

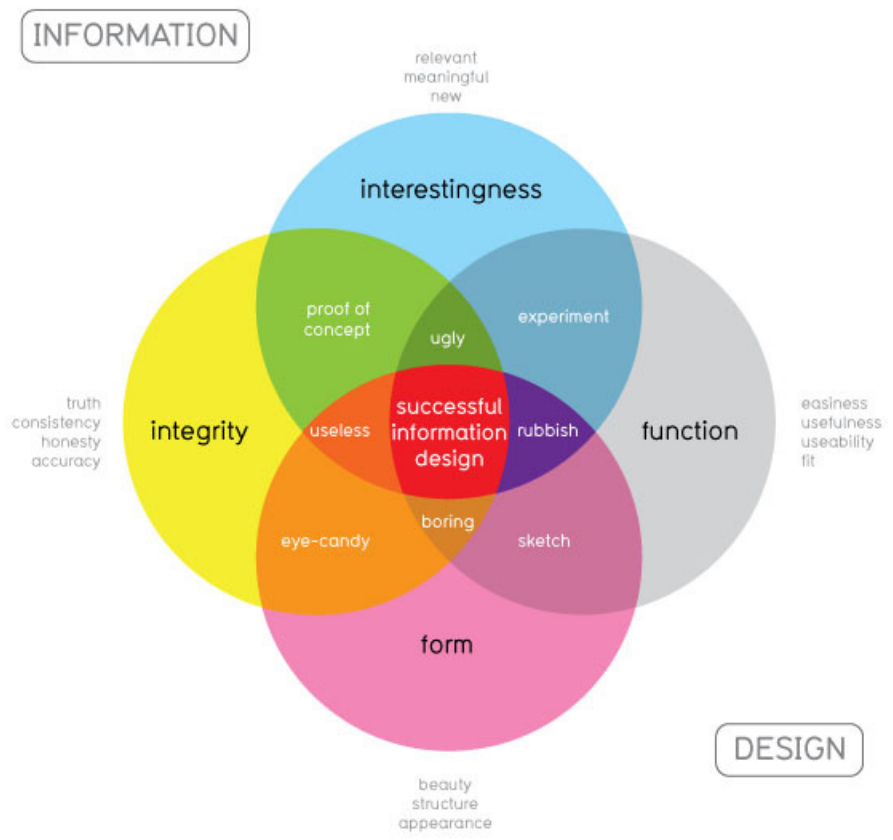

Successful information design is supposed to be honest, consistent and accurate to company's real status, also relevant, meaningful and new to make it interesting, as well as easy, usable and useful to be functional for the employees. And last but not least, even to say equally important the visual message needs to be well structuralized and ... beautiful. Not only in the internal communication but also integrated marketing communication to the global customers. In image economy it's the image that matters. And international organization's message is only as good as company's ability to share it through visual channels.

\section{Bibliography:}

Cornelissen, J. (2009), Corporate Communication. A guide to theory and practice, London: Sage. Entwistle, J. (2002), 'The Aesthetic Economy. The production of value in the field of fashion modeling', Journal of Consumer Culture, vol. 2, no. 3, 317-339.

Ingledew, J., (2011), The A-Z of visual ideas, London: Laurence King. 
Kliatchko, J. (2005), 'Towards a new definition of integrated marketing communications (IMC)', International Journal of Advertising, vol. 24, no. 1, pp. 7-34.

Machin, D. (2014), 'Visual Communication', Handbooks of Communication Science 4, DE GRUYTER MOUTON.

Meirelles, I. (2013), Design for Information: An Introduction to the Histories, Theories, and Best Practices Bebind Effective Information Visualizations, Rockport Publishers.

Oswald, L. R. (2012), Marketing semiotics. Signs, strategies and brand values, Oxford: Oxford University Press.

Oswald, L. R. (2015), Creating Value: The Theory and Practice of Marketing Semiotics Research, Oxford: Oxford University Press.

Rose, G. (2012), Visual Methodologies. An Introduction to Researching with Visual Materials, Open University Press.

Rozkwitalska, M. (2009), 'Cultural Dilemmas of International Management', Journal of Intercultural Management, vol. 1, no. 1, pp. 91-99.

Schroeder, J.E. (2004), 'Visual Consumption in the image economy', in Ekstrom K., Brembeck H. (ed.) Elusive economy, Oxford: Berg.

Web recourses:

O’Brien, C. (2015), Controversy Makes Whopper Virgins A Success For Burger King, http://thefutureofads.com/controversy-makes-whopper-virgins-a-success-for-burger-king

http://infosthetics.com/cgi-bin/mt/mt-search.cgi?search=successful+information+design \&IncludeBlogs $=1 \&$ limit $=20$ 